\title{
Surgery for recurrent biliary carcinoma: results for 27 recurrent cases
}

\author{
Takehiro Noji', Takahiro Tsuchikawa, Tomoko Mizota, Keisuke Okamura, Toru Nakamura, Eiji Tamoto,
}

Toshiaki Shichinohe and Satoshi Hirano

\begin{abstract}
Background: Various chemotherapies have been used as best practice to treat recurrent biliary malignancies. Conversely, relatively few surgeries have been described for recurrent extrahepatic biliary carcinoma (RExBC), so whether surgery for REXBC is feasible has remained unclear. This retrospective study was conducted to evaluate the feasibility of surgery for RExBC.

Methods: From February 2000 to January 2014, a total of 27 patients, comprising 18 patients with extrahepatic cholangiocarcinoma and 9 patients with gallbladder carcinoma, met our criteria for radical resection of RExBC (resection group). Sites of recurrence consisted of liver metastases (ten patients), local/percutaneous transhepatic cholangio drainage (PTCD) fistula recurrence (eight patients), bile duct recurrence (six patients), and lymph node recurrence (one patient). To evaluate the survival impact of resection, we compared 123 RExBC patients (resection group) with patients who received palliative care (palliative group).

Results: Morbidity and mortality rates in the resection group were $6.6 \%$ and $0 \%$, respectively. Overall cumulative 5 -year survival rates were $23.5 \%$ in the resection group and $0 \%$ in the palliative group. Median survival time was 21.6 months in the resection group and 9.5 months in the palliative group, showing a significant difference $(p<0.01)$. No significant differences in cumulative survival were seen between extrahepatic cholangiocarcinoma and gallbladder carcinoma in the resection group. In addition, no significant differences were seen between liver metastases, bile duct recurrence, and local/percutaneous transhepatic biliary drainage (PTBD) fistula recurrence in the resection group.
\end{abstract}

Conclusions: Surgery appears feasible for RExBC and offers longer survival for selected patients.

Keywords: Recurrent biliary malignancy, Extrahepatic cholangiocarcinoma, Gallbladder carcinoma, Surgery, Chemotherapy, Survival

\section{Background}

Long-term survival rates for extrahepatic biliary carcinoma (extrahepatic cholangiocarcinoma and gallbladder carcinoma) are thought to be improving. Fiveyear cumulative survival rates have been reported as 22 to $40 \%$ for extrahepatic cholangiocarcinoma and 8 to $65 \%$ for advanced gallbladder carcinoma [1-7]. For now, no evidence supports the use of adjuvant chemotherapy [8].

\footnotetext{
* Correspondence: drnoji@med.hokudai.ac.jp

Department of Gastroenterological Surgery II, Hokkaido University Graduate School of Medicine, Kita 15 Nishi 7, Kita-ku, Sapporo, Hokkaido 0608638, Japan
}

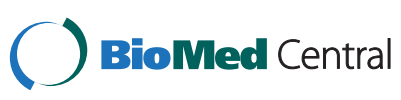

(c) 2015 Noji et al.; licensee BioMed Central. This is an Open Access article distributed under the terms of the Creative Commons Attribution License (http://creativecommons.org/licenses/by/4.0), which permits unrestricted use, distribution, and reproduction in any medium, provided the original work is properly credited. The Creative Commons Public Domain Dedication waiver (http://creativecommons.org/publicdomain/zero/1.0/) applies to the data made available in this article unless otherwise stated.
For recurrent biliary malignancies, various chemotherapies have been used as best practice [9]. Conversely, few surgeries for recurrent extrahepatic biliary carcinoma (RExBC) have been reported, because secondary (or more) resection for RExBC is known as an extremely demanding procedure. Most patients with extrahepatic biliary carcinoma undergo complex anatomical resection and reconstruction with radical lymphadenectomy around the hepatoduodenal ligament (skeletonization) in the primary surgery. Few reports have described surgical interventions for $\mathrm{RExBC}$, and those have mostly been case reports [10-14]. Whether surgery for RExBC is feasible thus remains unclear. 
We have performed aggressive surgical intervention for RExBC since 2000. This retrospective study was conducted to evaluate the feasibility of surgery for RExBC following radical operation.

\section{Methods}

Surgical indications for RExBC

Surgical indications for RExBC in our department at the time of the study were as follows:

A). All surgical intervention should be intended as R0 curative resection. Resectability was determined from several imaging modalities (computed tomography, magnetic resonance imaging, ultrasonography, endoscopic ultrasonography, ${ }^{18}$ F-fluorodeoxy glucose positron emission tomography). If multiple peritoneal disseminations or multiple metastases that were unable to be resected with curative intent were found, palliative procedures (gastrointestinal bypass or exploratory laparotomy only) were selected.

B). All candidates for surgical intervention were observed for at least 3 months with or without chemotherapy before resection. In addition, all candidates for surgical intervention should have isolated metastatic lesions. If a new metastatic lesion was found during this period, surgical intervention was not selected.

C). All candidates should have performance status 0 or 1 according to Eastern Cooperative Oncology Group criteria [15]. We used our criteria for hepatectomy in biliary malignancies, as described previously [16]. Anatomical variation and tumour location were also considered in determining resectability.

\section{Patients}

From February 2000 to January 2014, a total of 150 patients with RExBC were identified for whom follow-up of the complete clinical course in our department was available. Among these patients, a total of 27 patients (21 men, 6 women; median age 71 years; age range 45 to 83 years) met our surgical criteria for RExBC. The underlying pathology was extrahepatic cholangiocarcinoma in 18 patients and gallbladder carcinoma in 9 (resection group).

To evaluate the survival impact of resection for RExBC, we reviewed the remaining 123 unresectable patients (92 men, 31 women; median age 71 years; range 48 to 84 years) with RExBC (palliative group). This palliative group included eight patients who underwent exploratory laparotomy.

\section{Type of recurrence}

Recurrent sites consisted of liver metastases, local/percutaneous transhepatic biliary drainage (PTBD) fistula recurrence, bile duct recurrence, lymph node recurrence, and lung metastasis. Participants comprised ten patients with liver metastases, eight patients with PTBD fistula recurrence, six patients with bile duct recurrence, one patient with lymph node recurrence, and two patients with lung metastasis in the resection group, respectively (Table 1).

Concerning patients in the palliative group who underwent exploratory laparotomy, six patients with local/ PTBD recurrence showed peritoneal dissemination, and the remaining two patients with lymph node recurrence showed multiple lymph node metastases that were unable to be resected completely.

\section{Surgical procedure}

All resections were planned to have sufficient surgical margins. For liver metastases, several types of hepatectomy were performed. We planned various types of surgeries for local/PTBD fistula recurrence with sufficient margins. For bile duct recurrence, various major hepatectomies or pancreaticoduodenectomies were performed. For lymph nodal metastases, metastatic lymph node resection with concomitant resection of surrounding organ was performed. For lung metastases, partial lung resections were performed.

\section{Morbidity and mortality}

The Clavien-Dindo classification was used for defining morbidity and mortality [17]. Postoperative complications $\geq$ IIIa in the Clavien-Dindo classification were defined as morbidity.

Table 1 Patient characteristics in the resection and palliative groups

\begin{tabular}{|c|c|c|c|}
\hline Characteristics & $\begin{array}{l}\text { Resection group } \\
(n=27)\end{array}$ & $\begin{array}{l}\text { Palliative group } \\
(n=123)\end{array}$ & $p$ \\
\hline Age (years) ${ }^{a}$ & $71(45 \text { to } 83)^{b}$ & $71(48 \text { to } 84)^{b}$ & 0.77 \\
\hline Male/female (cases) & $21 / 6$ & $92 / 21$ & 0.81 \\
\hline \multicolumn{4}{|l|}{ Primary disease (cases) } \\
\hline $\begin{array}{l}\text { Extrahepatic } \\
\text { cholangiocarcinoma }\end{array}$ & 18 & 96 & 0.22 \\
\hline Gallbladder carcinoma & 9 & 27 & \\
\hline \multicolumn{4}{|l|}{ Recurrent site (cases) } \\
\hline Liver & 10 & 34 & - \\
\hline Bile duct & 6 & 5 & \\
\hline Lymph node & 1 & 14 & \\
\hline Local/PTBD fistula & 8 & 26 & \\
\hline Lung & 2 & 0 & \\
\hline Combined & 0 & 36 & \\
\hline Other & 0 & 8 & \\
\hline Chemotherapy (cases) & 12 & 52 & 1 \\
\hline $\begin{array}{l}\text { Disease-free interval } \\
\text { (months) }\end{array}$ & $\begin{array}{l}25.1 \\
(10.3 \text { to } 112.6)^{b}\end{array}$ & $\begin{array}{l}13.0 \\
(1.8 \text { to } 124.2)^{b}\end{array}$ & $<0.01$ \\
\hline
\end{tabular}

${ }^{a}$ Age at recurrence. ${ }^{b}$ Values represent median (range) for each parameter. PTBD, percutaneous transhepatic biliary drainage. 


\section{Evaluation of survival}

To evaluate the survival impact of RExBC, we calculated the length from the day on which recurrence was identified in this study.

\section{Statistics}

Statistical calculations were performed using Stat Flex software (Artech, Osaka, Japan) and the 'Exact Test' produced by Prof. S. Aoki (http://aoki2.si.gunma-u.ac.jp/exact/exact. html). The chi-square test, Fisher's exact, and MannWhitney $U$ tests were used as appropriate. Cumulative survival after surgery was calculated using the KaplanMeier method. The log-rank test was used to compare cumulative survival. Values of $p<0.05$ were considered significant.

\section{Consent}

This study was approved by the local institutional review board of Hokkaido University Hospital. And written informed consent was obtained from the patient for the publication of this report and any accompanying images.

\section{Results}

Two patients in the resection group underwent repeated resections for metastases. One patient with liver metastases underwent three resections, and the other patient with lung metastases underwent two resections. We performed 30 surgeries for the resection group, and 8 exploratory laparotomies in the palliative group. The resectability rate for the entire series was thus $79 \%$.

Disease-free intervals (DFIs) in the resection and palliative groups were 25.1 months (range 10.3 to 112.6 months) and 13.0 months (range 1.8 to 124.2 months), respectively. Significant differences in DFI were seen between the two groups $(p<0.01$, Table 1$)$.

We applied 30 various surgical procedures for the 27 cases in the resection group. Procedures and surgical results for the resection group are shown in Table 2. Morbidity and mortality rates were $6.6 \%$ and $0 \%$, respectively.

The overall cumulative 5-year survival rate was $23.6 \%$ in the resection group and $0 \%$ in the palliative group. Median survival time was 21.6 months in the resection group and 9.5 months in the palliative group, showing a significant difference between groups $(p<0.01)$ (Figure 1).

Three patients in the resection group achieved 5-year survival (one patient with liver metastases, one with lymph node metastasis, and one with local/PTBD fistula recurrence).

No significant differences in cumulative survival were seen between extrahepatic cholangiocarcinoma and gallbladder carcinoma in the resection group. No significant differences between liver metastases, bile duct recurrence, or local/PTBD fistula recurrence were seen
Table 2 Surgical procedure and results in the resection group: $\mathbf{3 0}$ surgeries for $\mathbf{2 7}$ resection group patients

\begin{tabular}{ll}
\hline Characteristics & $\begin{array}{l}\text { Surgeries } \\
(\boldsymbol{n}=\mathbf{3 0})\end{array}$ \\
\hline Operative procedure (cases) & 7 \\
Major hepatectomy & 11 \\
Non-anatomical hepatectomy & 2 \\
Pancreaticoduodenectomy & 3 \\
Lung resection & 2 \\
Tumour resection & 1 \\
Chest wall resection & 2 \\
Chest wall resection + non-anatomical hepatectomy & 1 \\
Non-anatomical hepatectomy + IVC/jejunum/colon/ & \\
diaphragm resection & 1 \\
Para-aortic lymphadenectomy + adrenalectomy & 2 \\
Morbidity (Clavien-Dindo $\geq$ IIla) (cases) & 0 \\
Mortality (cases) &
\end{tabular}

IVC, inferior venous cava.

in the resection group (Figure 2). Likewise, no significant differences were seen in survival between DFI $>24$ and $\leq 24$ months $(p=0.25)$.

No significant differences in survival were evident between extrahepatic cholangiocarcinoma and gallbladder carcinoma in the resection group patients (Figure 3 ).

\section{Discussion}

In general, almost all patients with recurrent biliary malignancy are treated using various chemotherapies. Some trials

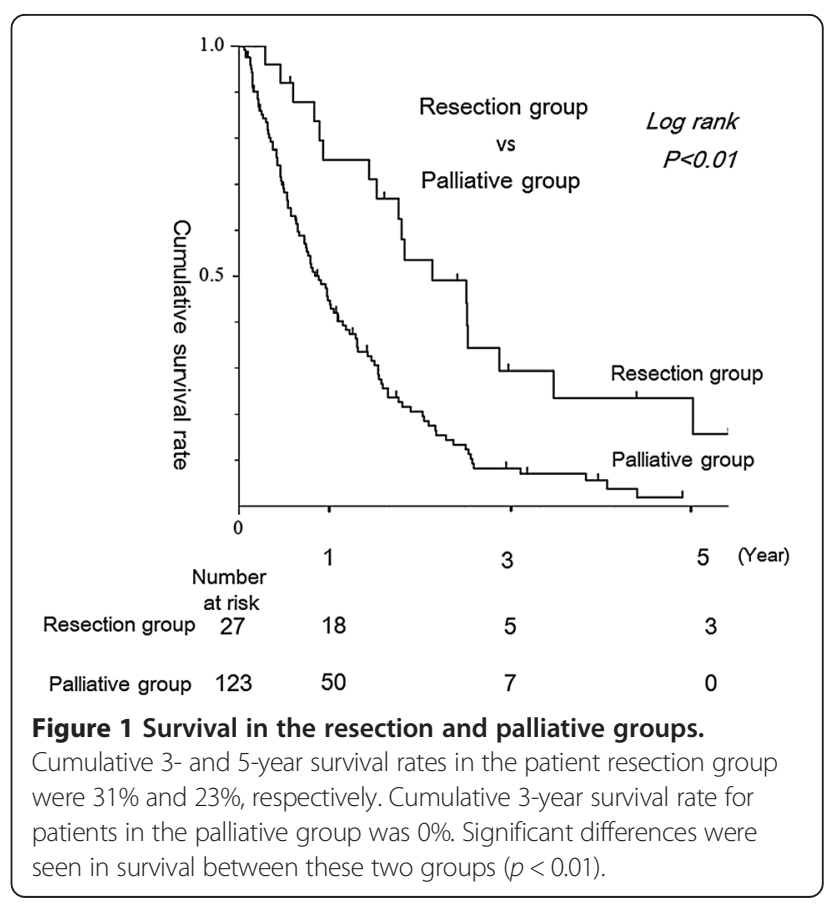




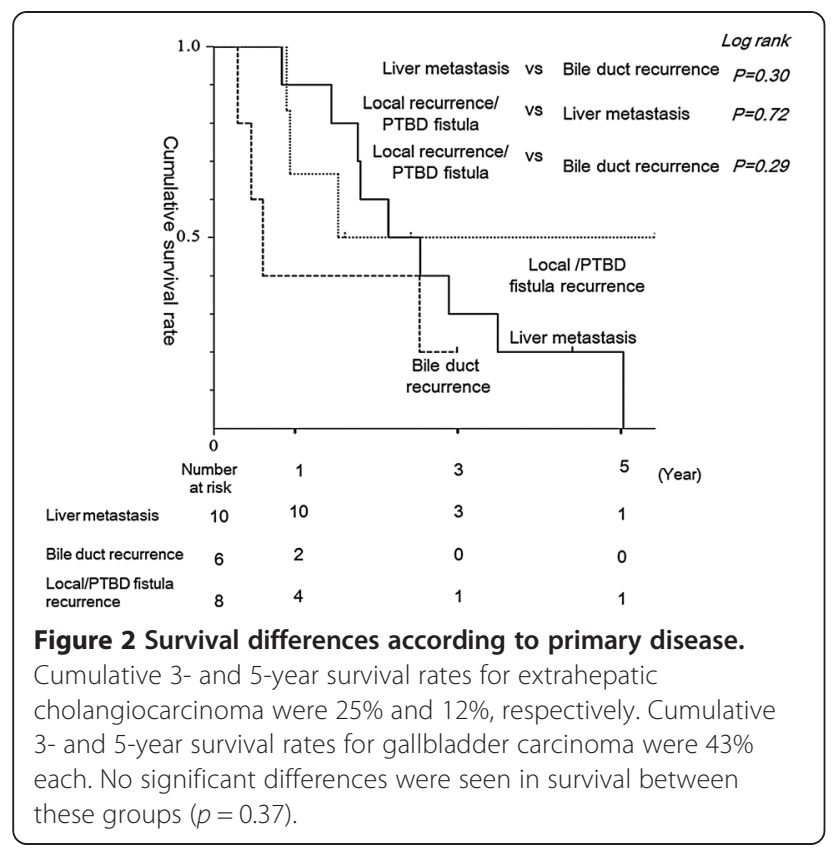

have revealed that gemcitabine- or S-1-based chemotherapy could provide clinical benefit to patients with recurrent biliary malignancies $[9,18-21]$. However, these chemotherapies had few patients with long-term survival, and median survival times have been reported as less than 13 months [9,18-21].

One of the most important questions for RExBC is whether surgical intervention is feasible. Our results suggest that surgical intervention for RExBC might be

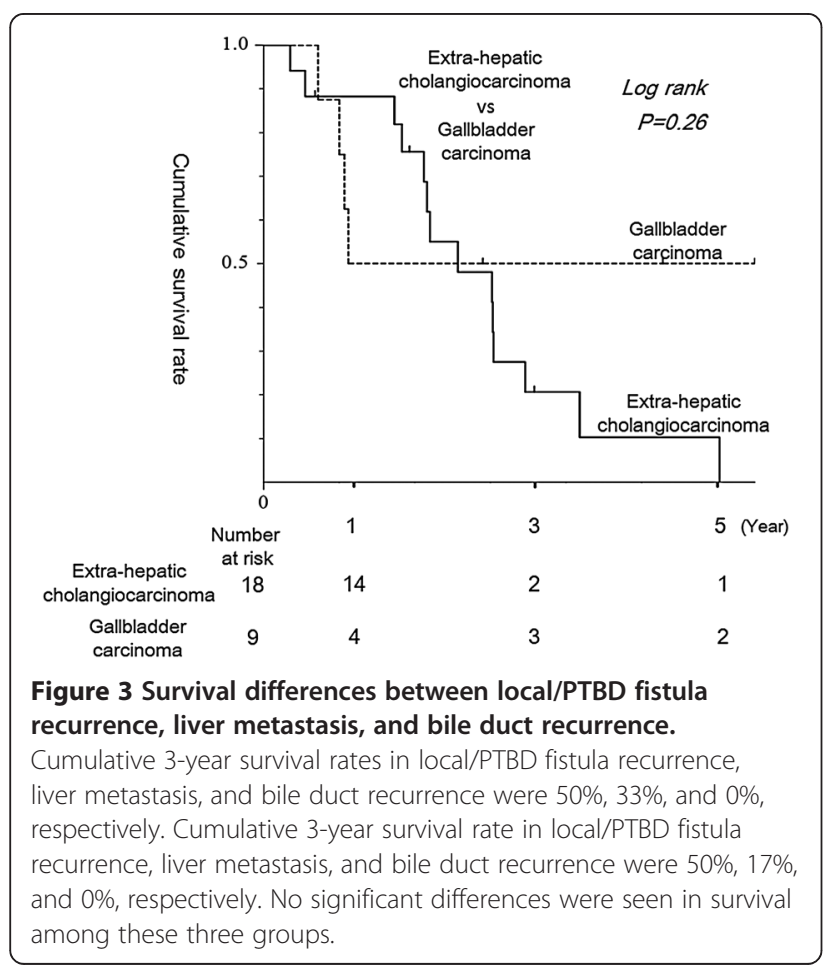

worth considering. Cumulative 5-year survival rate in the resection group was $23.6 \%$. We had low morbidity and no mortality in this series, and three patients survived for more than 5 years.

Concerning surgical indications for RExBC, only 1 report has referred to surgical results for RExBC; Song et al. reported surgical results for 27 patients with recurrent cholangiocarcinoma [22]. They showed that surgical resection for recurrent cholangiocarcinoma offers significant benefits for survival. However, because they merged recurrent intrahepatic cholangiocarcinoma (ICC) and recurrent extrahepatic cholangiocarcinoma and did not show operative results (operation time, operative bleeding, morbidity, or mortality) for their series, surgical indications for RExBC have remained unclear.

In terms of surgical intervention for recurrent ICC, few reports are available, and those reports have shown that surgical intervention for recurrent ICC would be feasible. Saiura et al. described five cases of repeat hepatectomy [23]. They had two patients with long-term survival. Okusaka et al. showed results for nine patients with various types of resection [19]. They performed curative resection for six of the nine patients and achieved relatively long survival for three. Fu et al. reported results for 19 patients with recurrent ICC treated using radiofrequency ablation (RFA) [24]. They showed a median overall survival of 30 months, and 1- and 3-year survival rates of $87.5 \%$ and $37.5 \%$, respectively.

Quite substantial differences might be thought to exist between extrahepatic cholangiocarcinoma and gallbladder carcinoma. However, recent studies for recurrent biliary carcinoma, such as the ABC-01 study and BT22 study, have included various types of RExBC $[19,21]$. Furthermore, our data showed no significant differences between extrahepatic cholangiocarcinoma and gallbladder carcinoma in either the palliative or the resection group. We therefore considered that inclusion of both extrahepatic cholangiocarcinoma and gallbladder carcinoma in our study was proper.

For gastrointestinal malignancies, the efficacy of repeat hepatectomy for colorectal liver metastases is widely accepted; however, the benefits of such treatment for intrahepatic recurrence of gastric cancer liver metastasis remain unclear [25-27]. Most patients have been treated using various chemotherapies [28]. This situation is thought to be similar to that for RExBC. However, several reports have suggested that hepatectomy for metastatic lesions from gastric cancer would lead to long-term survival [25-27,29]. Takemura et al. showed results for 64 gastric cancer patients with liver metastasis. They showed that median overall survival was 34 months, with 3- and 5-year survival rates of 50 and $37 \%$, respectively [26]. Baek et al. showed similar results [29]. Hwang et al. showed favourable median survival (27 months) for patients with 
RFA \pm chemotherapy and no extrahepatic metastasis [25]. These results of recurrent ICC, gastric cancer, and our results for RExBC might suggest that surgical intervention for selected patients with RExBC is feasible.

The next question is that if surgical intervention for RExBC is indeed feasible, for whom and when should surgery be performed?

We used two major criteria for surgical intervention for RExBC. Nobody would doubt our criterion that all surgical procedures should be performed with the intention of R0 curative resection. In other words, every patient for whom R0 resection is considered possible would represent a surgical candidate.

Concerning the site of recurrence, we achieved successful resection for all candidates with bile duct recurrence and liver metastasis. Three of ten patients with liver metastasis were able to survive over 3 years after resection at the site of recurrence.

For bile duct recurrences, we have some doubts about surgical indications. We needed to perform demanding extended resection in the form of major hepatectomy or pancreaticoduodenectomy. However, the survival rate with bile duct recurrence tended to be lower than that with other types of recurrence, although no significant differences were identified (Figure 3).

We achieved lower resectability rates for patients with local/PTBD recurrence or lymph node recurrence than for patients with other recurrences. That means some patients were not adequately diagnosed in the preoperative survey. Our previous reports have shown that diagnosing lymph node metastasis preoperatively is difficult [30,31]. Diagnosing peritoneal disseminations preoperatively must likewise be difficult [32].

However, our data only included a small number of patients with peritoneal metastases or para-aortic lymph node metastasis for resection with curative intent. We achieved long survival for patients with para-aortic lymph node metastasis or local/PTBD fistula recurrence ('localized' peritoneal recurrence), and one patient achieved more than a 5 -year survival. This suggests that surgical intervention is also feasible for selected patients with local/PTBD or lymph node recurrence.

When should surgery be performed? We observed all surgical candidates for at least 3 months with or without chemotherapy before surgery. This criterion was introduced based on our personal experience without objective evidence as such. However, we believe this criterion could allow exclusion of patients with a 'rapidly growing tumor' or patients with a 'widely disseminating tumor.'

With regard to the timing of surgery, no significant criteria have been described in recurrent ICC series [19,23,24]. On the other hand, in patients with liver metastases from gastric cancer, Takemura identified disease-free interval, tumour size, and primary tumour stage as prognostic factors for survival $[26,27]$. Our data showed no significant effect of operative interval on survival.

Our criteria for RExBC led us to a $79 \%$ resectability rate, which was considered satisfactory.

This study had several limitations. First, it was a small, retrospective study and was not an intention-to-treat analysis. Whether surgical intervention is feasible thus remains in question. Second, whether neoadjuvant or adjuvant therapy is effective for resectable RExBC also remains unclear. Third, this study excluded carcinoma of the papilla of Vater. The feasibility of surgery for recurrent carcinoma of the papilla of Vater thus remains unclear.

These limitations would be best addressed in a future multi-centre study.

\section{Conclusions}

In conclusion, despite these limitations, surgical intervention appears to offer improved survival in select patients with RExBC. Appropriate surgical indications and adjuvant therapy for RExBC should be investigated in a larger-scale study.

\section{Abbreviations}

DFI: disease-free interval; ICC: intrahepatic cholangiocarcinoma;

PTBD: percutaneous transhepatic biliary drainage; RFA: radiofrequency

ablation; RExBC: recurrent extrahepatic biliary carcinoma.

\section{Competing interests}

The authors declare that they have no competing interests.

\section{Authors' contributions}

TN and SH carried out the data collection and analysis, the statistical part, and the discussion part. TM, TT, KO, TN, TS, and ET carried out the data collection and discussion part. $\Pi \mathrm{T}$ and $\mathrm{SH}$ carried out the surgery. All authors read and approved the final manuscript.

Received: 4 September 2014 Accepted: 9 February 2015

Published online: 27 February 2015

\section{References}

1. Hirano S, Kondo S, Tanaka E, Shichinohe T, Tsuchikawa T, Kato K, et al. Outcome of surgical treatment of hilar cholangiocarcinoma: a special reference to postoperative morbidity and mortality. J Hepatobiliary Pancreat Sci. 2010;17:455-62.

2. Kondo S, Hirano S, Ambo Y, Tanaka E, Okushiba S, Morikawa T, et al. Forty consecutive resections of hilar cholangiocarcinoma with no postoperative mortality and no positive ductal margins: results of a prospective study. Ann Surg. 2004;240:95-101.

3. Igami $T$, Nishio $H$, Ebata $T$, Yokoyama $Y$, Sugawara $G$, Nimura $Y$, et al. Surgical treatment of hilar cholangiocarcinoma in the "new era": the Nagoya University experience. J Hepatobiliary Pancreat Sci. 2010;17:449-54.

4. Ito K, Ito H, Allen PJ, Gonen M, Klimstra D, D'Angelica MI, et al. Adequate lymph node assessment for extrahepatic bile duct adenocarcinoma. Ann Surg. 2010;251:675-81.

5. Noji T, Tsuchikawa T, Okamura K, Shichinohe T, Tanaka E, Hirano S. Surgical outcome of hilar plate resection: extended hilar bile duct resection without hepatectomy. J Gastrointest Surg. 2014;18:1131-7.

6. Nishio H, Ebata T, Yokoyama Y, Igami T, Sugawara G, Nagino M. Gallbladder cancer involving the extrahepatic bile duct is worthy of resection. Ann Surg. 2011;253:953-60.

7. Ruys AT, van Haelst S, Busch OR, Rauws EA, Gouma DJ, van Gulik TM. Long-term survival in hilar cholangiocarcinoma also possible in unresectable patients. World J Surg. 2012;36:2179-86. 
8. Konishi M. Adjuvant chemotherapy for resectable biliary tract cancer: current status and future direction. J Hepatobiliary Pancreat Sci. 2012;19:301-5.

9. Furuse J, Kasuga A, Takasu A, Kitamura H, Nagashima F. Role of chemotherapy in treatments for biliary tract cancer. J Hepatobiliary Pancreat Sci. 2012;19:337-41.

10. Scaringi S, Nesi G, Bargellini T, Batignani G, Tonelli F. Iterative surgical resection of a recurrent gallbladder carcinoma with long-term survival: report of a case. In Vivo. 2010;24:215-7.

11. Shinkai H, Kimura W, Sata N, Muto T, Nagai H. A case of gallbladder cancer with para-aortic lymph node metastasis who has survived more than seven years after the primary extended radical operation. Hepatogastroenterology. 1996;43:1370-6.

12. Ito Y, Tajima Y, Fujita F, Tsutsumi R, Kuroki T, Kanematsu T. Solitary recurrence of hilar cholangiocarcinoma in a mediastinal lymph node two years after curative resection. World J Gastroenterol. 2007;13:2243-6.

13. Amemiya T, Yokoyama $Y$, Oda K, Nishio H, Ebata T, Abe T, et al. A patient with gallbladder cancer with paraaortic lymph node and hepatic metastases who has survived for more than 13 years after the primary extended radical operation. J Hepato-Biliary-Pancreat Surg. 2008;15:648-51.

14. Ota Y, Matsuyama R, Taniguchi K, Ueda M, Takeda K, Tanaka K, et al. Solitary rib recurrence of hilar cholangiocarcinoma 10 years after resection: report of a case. Clin J Gastroenterol. 2013;6:485-9.

15. Oken MM, Creech RH, Tormey DC, Horton J, Davis TE, McFadden ET, et al. Toxicity and response criteria of the Eastern Cooperative Oncology Group. Am J Clin Oncol. 1982:5:649-55.

16. Hirano S, Tanaka E, Shichinohe T, Suzuki O, Hazama K, Kitagami H, et al. Treatment strategy for hilar cholangiocarcinoma, with special reference to the limits of ductal resection in right-sided hepatectomies. J Hepato-Biliary-Pancreat Surg. 2007;14:429-33.

17. Clavien PA, Barkun J, de Oliveira ML, Vauthey JN, Dindo D, Schulick RD, et al. The Clavien-Dindo classification of surgical complications: five-year experience. Ann Surg. 2009;250:187-96.

18. Morizane C, Okusaka T, Mizusawa J, Takashima A, Ueno M, Ikeda M, et al. Randomized phase II study of gemcitabine plus S-1 versus S-1 in advanced biliary tract cancer: a Japan Clinical Oncology Group trial (JCOG 0805). Cancer Sci. 2013;104:1211-6.

19. Okusaka T, Nakachi K, Fukutomi A, Mizuno N, Ohkawa S, Funakoshi A, et al. Gemcitabine alone or in combination with cisplatin in patients with biliary tract cancer: a comparative multicentre study in Japan. Br J Cancer. 2010;103:469-74

20. Valle JW. Advances in the treatment of metastatic or unresectable biliary tract cancer. Ann Oncol. 2010;21 Suppl 7:vii345-8.

21. Valle J, Wasan H, Palmer DH, Cunningham D, Anthoney A, Maraveyas A, et al. Cisplatin plus gemcitabine versus gemcitabine for biliary tract cancer. N Engl J Med. 2010;362:1273-81.

22. Song SC, Heo JS, Choi DW, Choi SH, Kim WS, Kim MJ. Survival benefits of surgical resection in recurrent cholangiocarcinoma. J Korean Surg Soc. 2011;81:187-94.

23. Saiura A, Yamamoto J, Kokudo N, Koga R, Seki M, Hiki N, et al. Intrahepatic cholangiocarcinoma: analysis of 44 consecutive resected cases including 5 cases with repeat resections. Am J Surg. 2011;201:203-8.

24. Fu Y, Yang W, Wu W, Yan K, Xing BC, Chen MH. Radiofrequency ablation for postoperative recurrences of intrahepatic cholangiocarcinoma. Chin J Cancer Res. 2011;23:295-300.

25. Hwang SE, Yang DH, Kim CY. Prognostic factors for survival in patients with hepatic recurrence after curative resection of gastric cancer. World I Surg. 2009;33:1468-72.

26. Takemura N, Saiura A, Koga R, Arita J, Yoshioka R, Ono Y, et al. Long-term outcomes after surgical resection for gastric cancer liver metastasis: an analysis of 64 macroscopically complete resections. Langenbecks Arch Surg. 2012;397:951-7.

27. Takemura N, Saiura A, Koga R, Yoshioka R, Yamamoto J, Kokudo N. Repeat hepatectomy for recurrent liver metastasis from gastric carcinoma. World J Surg. 2013;37:2664-70.

28. Boku N. Chemotherapy for metastatic gastric cancer in Japan. Int J Clin Oncol. 2008;13:483-7.

29. Baek HU, Kim SB, Cho EH, Jin SH, Yu HJ, Lee Jl, et al. Hepatic resection for hepatic metastases from gastric adenocarcinoma. J Gastric Cancer. 2013;13:86-92
30. Noji T, Kondo S, Hirano S, Tanaka E, Ambo Y, Kawarada Y, et al. CT evaluation of paraaortic lymph node metastasis in patients with biliary cancer. J Gastroenterol. 2005;40:739-43.

31. Noji T, Kondo S, Hirano S, Tanaka E, Suzuki O, Shichinohe T. Computed tomography evaluation of regional lymph node metastases in patients with biliary cancer. Br J Surg. 2008;95:92-6.

32. Kim SJ, Kim HH, Kim YH, Hwang SH, Lee HS, Park Do J, et al. Peritoneal metastasis: detection with 16- or 64-detector row CT in patients undergoing surgery for gastric cancer. Radiology. 2009;253:407-15.

\section{Submit your next manuscript to BioMed Central and take full advantage of:}

- Convenient online submission

- Thorough peer review

- No space constraints or color figure charges

- Immediate publication on acceptance

- Inclusion in PubMed, CAS, Scopus and Google Scholar

- Research which is freely available for redistribution

Submit your manuscript at www.biomedcentral.com/submit 